\title{
Peran Daya Tarik Desa Wisata dan Community Based Tourism dalam Membangun Citra Desa Wisata
}

\author{
Syarif Hidayatullah ${ }^{1}$, Irany Windhyastiti ${ }^{1 *}$, Abdul Waris ${ }^{2}$ \\ ${ }^{1}$ Program Studi Manajemen, Fakultas Ekonomi dan Bisnis, Universitas Merdeka \\ Malang, Malang, Indonesia \\ ${ }^{2}$ Program Studi Manajemen Pemasaran, Politeknik Negeri Malang, Malang, \\ Indonesia \\ *irani.windhyastiti@unmer.ac.id
}

\begin{abstract}
This study aims to determine: 1) the influence of tourist village attraction to image of tourist village; 2) the influence of community based tourism to image of tourist village; and 3) the influence of community based tourism in strengthening tourist village attraction to images of tourist village. This research was conducted in Batu City with a sample of 120 tourists. The results show: 1) the tourist village attraction has a significant effect to images of tourist village; 2) the influence of community based tourism has a significant effect to images of tourist village; and 3) the community based tourism does not strengthen the influence of tourist village attraction to images of tourist village, but the direct influence of Community Based Tourism on the image of a tourist village is greater than the direct effect of the attractiveness of a tourist village on the image of a tourist village
\end{abstract}

Keywords: Community Based Tourism, Image of Tourist Village, Tourist Village Attraction

\section{PENDAHULUAN}

Visi pembangunan Kota Batu berdasarkan RPJP adalah "Terwujudnya Kota Batu sebagai Sentra Pariwisata berbasis Pertanian yang Berdaya Saing menuju Masyarakat Madani. Visi ini diwujudkan dalam target pencapaian Tri Asa Kota Batu pada tahun 2025 yaitu sebagai pusat pendidikan yang berdaya saing, pusat pertanian organik dan pusat pariwisata berdaya saing internasional. Dalam rangka mencapai salah satu Tri Asa yaitu sebagai pusat pariwisata yang berdaya saing internasional yang dikuatkan dengan citra Kota Batu sebagai "Little Swiss in Java", Pemerintah Kota Batu berusaha menarik investor dengan berbagai fasilitas terutama dalam kemudahan perijinan investasi. Salah satu dampak dalam upaya tersebut adalah

semakin banyaknya objek wisata buatan di Kota Batu yang diharapkan mampu menarik banyak wisatawan. Saat ini terdapat lebih dari 20 objek wisata buatan di Kota Batu termasuk Jatim Park 1, Jatim Park 2, Jatim Park 3, Museum Angkut, Predator dan lain-lain. Langkah ini telah membawa Kota Batu untuk mendapatkan prestasi luar biasa. Jumlah wisatawan di Kota Batu pada 2019 mencapai 6.047.460 wisatawan (Statistik, 2020). Namun sayangnya, meskipun jumlah wisatawan Kota Batu cukup besar dan mampu berkontribusi besar pada PAD, lebih banyak wisatawan menghabiskan uang mereka pada objek wisata buatan yang dimiliki oleh investor besar (Jatim Park Group), sehingga masyarakat Kota Batu secara umum tidak merasakan manfaat kemajuan Kota Wisata 
Batu secara langsung. Oleh karena itu, pemerintah kemudian mencoba mengembangkan desa wisata dengan harapan dapat secara langsung melibatkan masyarakat dalam kegiatan pariwisata. Selain itu, melalui pengembangan desa wisata Kota Batu, diharapkan Kota Batu juga dapat menjadi salah satu tujuan wisata internasional, mengingat bahwa turis asing lebih tertarik pada wisata alam daripada wisata buatan. Saat ini jumlah desa wisata di Kota Batu mencapai sekitar 12 desa wisata dengan berbagai potensi seperti apel, bunga, kerajinan dan lainnya. Untuk mendukung pengembangan Desa Wisata di Kota Batu, yang penting dibutuhkan adalah peran dan kontribusi penting Pokdarwis (Kelompok Kesadaran Pariwisata) dalam pengembangan pariwisata di wilayah tersebut. Oleh karena itu dukungan secara kontinu dan pembinaan atas keberadaan Pokdarwis perlu dilakukan sehingga dapat memainkan peran yang lebih optimal dalam mengerakkan partisipasi masyarakat guna terciptanya suasana dan lingkungan yang kondusif bagi pertumbuhan dan pengembangan kegiatan pariwisata di sekitar tujuan wisata. Berkaitan dengan pentingnya pengembangan desa wisata di Kota Batu sebagai penarik wisatawan asing, maka bagaimana membangun citra desa wisata untuk dapat menarik wisatawan sebagai langkah awal yang harus dilakukan. Sehingga ini menarik untuk ditelaah lebih detail kemudian dianalisis sejauh mana peran daya tarik desa wisata dan community based tourism yang secara konkrit di desa wisata lebih dikenal dengan Pokdarwis dalam membangun citra desa wisata.

\section{Desa Wisata dan Pengembangan Desa Wisata}

Desa wisata merupakan perpaduan antara pemandangan, akomodasi, dan fasilitas pendukung yang diwujudkan dalam struktur kehidupan sosial dan memasukkan prosedur dan tradisi yang berlaku (Permen Kebudayaan dan Pariwisata, 2010). Hal yang penting dalam pengembangan desa wisata adalah adanya keterlibatan masyarakat, karena pemahaman sejauh mana potensi yang dimiliki oleh wilayah tersebut diperoleh dari masyarakat. Selain itu, pentingnya keterlibatan masyarakat untuk memastikan adanya dukungan oleh masyarakat serta manfaat yang akan diperoleh sesuai dengan kebutuhan dan menguntungkan warga setempat. Oleh karena itu, peran warga dalam pengembangan pariwisata perlu ditingkatkan sebagai bagian yang tidak terpisahkan. Partisipasi masyarakat seharusnya tidak hanya berfokus pada mendorong proses penguatan kapasitas masyarakat lokal, tetapi juga sebagai mekanisme untuk meningkatkan kegiatan pemberdayaan masyarakat dan berpartisipasi dalam pembangunan bersama. Bentuk partisipasi masyarakat dapat berupa penyediaan fasilitas akomodasi: misalnya, menjadikan rumah-rumah penduduk menjadi homestay (penginapan), menyediakan kebutuhan konsumsi pariwisata, menyediakan pemandu wisata, menyediakan transportasi lokal, membuat pertunjukan kesenian, dan lain-lain.

Kepariwisataan membutuhkan berbagai usaha pemberdayaan (empowerment), karena memungkinkan masyarakat memperoleh manfaat positif dari kegiatan pembangunan yang dilakukan, dan memungkinkan masyarakat berperan aktif dan optimal serta meningkatkan kesejahteraannya. Aspek mendasar dari keberhasilan pengembangan pariwisata adalah menciptakan lingkungan dan suasana yang kondusif untuk mendorong tumbuh dan berkembangnya kegiatan pariwisata di wilayah tersebut. Dalam hal ini kelompok sadar wisata atau Pokdarwis adalah organisasi informal yang anggotanya terdiri dari anggota masyarakat yang peduli terhadap pengembangan pariwisata lokal. Selain Pokdarwis, peran serta tokoh masyarakat dan pemangku kepentingan masyarakat menjadi relevan dan penting. Sebagai salah satu "faktor pendorong", memberikan dukungan untuk menciptakan lingkungan dan suasana yang menguntungkan di wilayah tersebut. Selain itu, diharapkan semua stakeholder yang terlibat dapat bersinergi untuk memberikan dampak positif bagi pengembangan destinasi wisata yang lebih luas di daerah. 
Community Based Tourism (CBT)

Community Based Tourism (CBT) merupakan pariwisata yang memiliki pemahaman dan kesadaran terhadap kelestarian budaya, sosial, dan lingkungan. Pariwisata dengan bentuk seperti ini dimiliki dan dikelola oleh masyarakat dan untuk masyarakat. Dimana CBT berperan dalam membantu wisatawan meningkatkan kesadaran dan belajar tentang masyarakat dan gaya hidup dengan kearifan lokal. Oleh karena itu, CBT berbeda dengan pariwisata massal. Mengingat bahwa industri pariwisata yang diasumsikan harus dimulai dari memahami kebutuhan masyarakat sebagai konsekuensi dari model pengembangan pariwisata berorientasi CBT, maka pengembangan pariwisata haruslah berupaya agar lebih bermanfaat bagi kebutuhan, gagasan dan peluang masyarakat setempat (Pinel DP, 1998). CBT tidak bertujuan untuk memaksimalkan keuntungan bagi investor karena CBT bukan sebuah bisnis wisata melainkan berorientasi pada pemanfaatan sumber daya lingkungan sebagai dampak pariwisata bagi masyarakat. CBT berawal dari strategi pemberdayaan masyarakat, menggunakan pariwisata sebagai alat untuk memperkuat kapasitas masyarakat pedesaan/lokal untuk berorganisasi.

Prinsip-prinsip yang digunakan dalam konsep CBT adalah sebagai alat pengembangan masyarakat bagi masyarakat setempat, misalnya: mengakui, mendukung dan mempromosikan bahwa kegiatan pariwisata tersebut adalah milik masyarakat, setiap tahap sejak awal selalu melibatkan anggota masyarakat, meningkatkan kualitas hidup, meningkatkan kebanggaan masyarakat, menjaga kelestarian lingkungan, mempertahankan karakteristik dan budaya lokal yang unik, membantu meningkatkan pembelajaran lintas budaya, menghormati perbedaan budaya dan martabat manusia, dan mendistribusikan manfaat secara adil di antara anggota masyarakat, dan berkontribusi pada persentase penghasilan proyek masyarakat yang ditentukan.

Konsep pengembangan pariwisata berbasis masyarakat di populerkan oleh
Murphy, dimana Murphy berpandangan jika produk pariwisata diekspresikan dan dikonsumsi secara lokal. Produk pariwisata dan konsumen harus terlihat oleh penduduk setempat karena sering kali masyarakat sangat sadar akan dampak pariwisata. Oleh karena itu, melibatkan masyarakat setempat merupakan sebuah keharusan dalam pariwisata, sebagai bagian dari produk pariwisata. Dalam pengambilan keputusan masyarakat lokal harus dilibatkan dalam pengembangan pariwisata, hal ini tidak terlepas dari peran masyarakat lokal yang akan menanggung dampak kumulatif dari pengembangan pariwisata dan mereka perlu memperoleh investasi dan income yang lebih besar, bagaimana pariwisata dapat dikemas dan dijual sebagai produk pariwisata. (Murphy, 1985). Sedangkan Getz dan Jamal (1994) meberikan kritik tehadap model Murphy, karena tidak menawarkan blue print untuk menerapkan modelnya dalam bentuk konkret. Konsep Murphy dalam pelaksanaannya masih memiliki banyak hambatan. (Getz \& Jamal, 1994). Integritas dan keaslian serta daya saing produk wisata perlu untuk dipelihara dengan cara adanya partisipasi masyarakat (Gunn, 1988). Tujuan model perencanaan pariwisata seperti ini lebih diprioritaskan untuk memelihara daya tarik dan keunikan, sebenarnya masih lebih mengarah pada pendekatan top-down, berorientasi bisnis dan ekonomi (Bahaire \& Elliott-White, 1999). Faktor yang sangat penting dalam keberhasilan produk pariwisata adalah keterlibatan masyarakat. Dalam proses pengembangan pariwisata pola pendekatan masyarakat ini dapat menjadi standar.

Pada sekitar tahun 1990an, sejalan dengan berkembangnya minat dalam peningkatan produk wisata lestari, bentuk keterlibatan masyarakat menjadi sangat urgent. Partisipasi masyarakat ini menjadi urgent untuk mencapai wisata yang sustainability dan menciptakan pariwisata yang berkualitas. Kemudian landasan teori ini dikembangkan oleh Getz dan Jamal (1994), Dengan menganalisis sifat dan tujuan dari mode kerjasama yang berbeda, direkomendasikan agar masyarakat 
berpartisipasi dalam perencanaan dan pengembangan pariwisata. Proses pengambilan keputusan bersama di antara pemangku kepentingan otonom dari bidang antar-organisasi untuk menyelesaikan masalah terkait pariwisata atau manajemen merupakan interpretasi dari sebuah kolaborasi (Getz \& Jamal, 1994). Proses kolaborasi meliputi beberapa hal : 1) Pengaturan masalah dengan melakukan identifikasi pemangku kepentingan utama dan isu; 2) Pengaturan arah dengan cara berbagi interpretasi kolaboratif, dan menghargai tujuan bersama; 3) Melakukan penataan dan pelaksanaan, dan 4) Kelembagaan.

\section{Pengaruh Daya Tarik Wisata Terhadap Citra Daerah Wisata}

Citra merek (brand) ialah bagian dari brand yang dapat dikenali tetapi tidak dapat diucapkan, seperti simbol, desain, huruf atau warna khusus, atau persepsi pelanggan terhadap produk atau jasa yang diwakili oleh brand tersebut (Surachman, 2008). Sedangkan yang dimaksud citra pariwisata menurut Pitana dan Diarta mengacu pada kepercayaan wisatawan terhadap produk atau jasa yang mereka beli atau akan beli. Citra destinasi juga dapat dibentuk, artinya tidak selalu dari berdasar pengalaman atau fakta, namun juga berasal dari motivasi atau daya dorong yang kuat dari wisatawan untuk berwisata ke destinasi pariwisata. Berdasarkan penilaian wisatawan citra destinasi pariwisata antara satu orang dengan yang lainnya bisa berbeda (Pitana IG \& Diarta I K. S., 2009). Coban menjelaskan dalam penelitiannya, citra destinasi terdiri dari citra kognitif (cognitive image) yang dikenal dengan penilaian rasional dan citra afektif (affective image) yang dikenal dengan penilaian emosional dari destinasi itu sendiri. Menurut Coban, keyakinan dan informasi seseorang tentang suatu destinasi disebut sebagai cognitive image. Adapun cognitive image memiliki aspek atraksi wisata (touristy traditions), atraksi budaya (cultural attractions), faktor lingkungan alam (natural environment), ekonomi (variety and economical factors), fasilitas dasar (basic facilities), dan faktor aksesibilitas dan substruktur pariwisata (touristy substructures and access) (Coban S, 2012).

Sedangkan penelitian Chi, membuat sembilan klasifikasi atribut yang dapat mempengaruhi citra destinasi, antara lain: 1) lingkungan alamiah, 2) atribut alamiah, 3) suasana destinasi, 4) aspek budaya, sejarah dan seni, 5) infrastruktur pariwisata, 6) kesempatan bagi wisatawan untuk bersenang-senang dan berekreasi, 7) lingkungan sosial, 8) fasilitas umum, dan 9) faktor ekonomi dan politik. Wisatawan mungkin akan kembali berkunjung (revisit) atau bahkan merekomendasi kepada keluarga dan temannya sebagai calon wisatawan (recommend travel destinations), hal ini adalah sebuah konsekuensi logis karena pariwisata merupakan sebuah produk (Chi Gengqing, 2005). Milman dan Pizam (1995) Dari segi kognitif, ia menyediakan tiga elemen yang membentuk citra destinasi, yaitu, tempat pemandangan, perilaku tuan rumah, dan lingkungan destinasi wisata, seperti iklim, fasilitas, dan lain-lain. (Milman A \& Pizam A, 1995).

Sejalan dengan hasil-hasil penelitian di atas, penelitian di daerah wisata ternama di Indonesia yaitu Bali menunjukkan bahwa citra destinasi Bali dipengaruhi secara signifikan oleh faktor penarik wisatawan mancanegara. Terdapat tiga faktor utama yang dapat menjadi daya tarik destinasi pariwisata Bali, antara lain adalah budaya, keindahan alam, dan sejarah Bali. Uraian lain dari narasumber adalah bahwa faktor-faktor yang menjadi daya tarik Bali adalah suasana liburan yang baik, ketersediaan makanan dan minuman, event dan festival, harga yang menarik di Bali, fasilitas dan pelayanan wisata yang baik, dan negara asal, serta faktor keamanan pulau Bali juga menjadi perhatian (Utama, 2017).

\section{Pengaruh Community Based Tourism Terhadap Citra Daerah Wisata}

Penilaian, kesan, atau gambaran yang dimiliki seseorang terhadap objek wisata merupakan citra pariwisata di suatu daerah. Citra pariwisata yang ada di suatu daerah, 
tidak hanya ditunjukkan oleh objek wisatanya saja, tetapi juga dari cenderamata yang dihasilkan seperti kerajinan tangan batik, pernak-pernik kayu, bambu, perak. Hal ini menunjukkan bahwa citra pariwisata daerah bisa dibentuk dari peran community development (Widya Amelia, 2016). Hasil penelitian di heritage site Italia juga menunjukkan bahwa komitmen masyarakat mempengaruhi keterlibatan warga masyarakat dalam kegiatan promosi sehingga dapat membantu membangun komunikasi yang efektif dan dapat diandalkan dengan wisatawan (Vollero, Conte, Bottoni, \& Siano, 2018).

Uraian di atas sebagai dasar dalam membuat hipotesis berikut ini:

$\mathrm{H}_{1}$ : Daya tarik desa wisata mempunyai pengaruh positif dan signifikan terhadap citra desa wisata

$\mathrm{H}_{2}$ : Community Based Tourism mempunyai pengaruh positif dan signifikan terhadap citra desa wisata

$\mathrm{H}_{3}$ : Community Based Tourism memperkuat pengaruh daya tarik desa wisata terhadap citra desa wisata

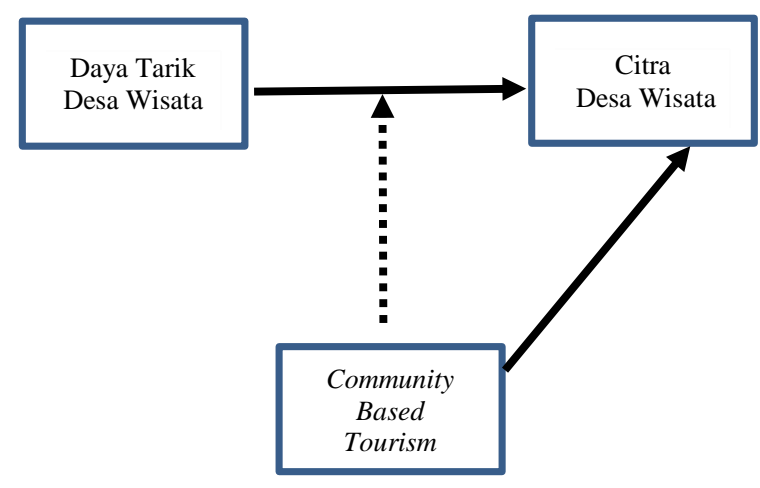

Gambar 1. Kerangka Konseptual

\section{METODE}

Penelitian dilakukan di 3 desa wisata di Kota Batu, Jawa Timur, yaitu Coban Talun, Coban Rais dan Coban Puteri dengan 120 responden diambil secara random sampling. PLS digunakan untuk analisis data. Variabel daya tarik desa wisata diukur dengan indikator: 1) atraksi, 2) fasilitas, 3) substruktur dan akses wisata, dan 4) harga. Variabel Community Based Tourism diukur dengan: 1) keramahan dari masyarakat, pedagang, dan semua sektor jasa wisata, 2) tingkat aktivitas masyarakat dalam pengelolaan wisata, 3) profesionalisme masyarakat dalam pengelolaan pariwisata. Citra desa wisata diukur dengan : 1) wisata yang menyenangkan, 2) wisata yang memberikan nyaman, 3) wisata yang unik, 4) wisata pendidikan dan 5) kelayakan menjadi identitas desa.

\section{HASIL DAN PEMBAHASAN \\ Gambaran Desa Wisata}

Desa wisata Coban Talun, Coban Puteri dan Coban Rais yang merupakan desa target penelitian telah melakukan dan merencanakan beberapa bentuk program yang ditawarkan kepada wisatawan seperti tampak pada Tabel 1. Tabel 1 menunjukkan tentang existing program yang selama ini sudah dijalankan di ketiga desa wisata dan rencana kegiatan yang akan dilakukan untuk pengembangan desa wisata ke depan. Dari Tabel 1, sudah nampak bahwa di 3 desa wisata Coban Talun, Coban Puteri dan Coban Rais masing-masing Pokdarwis telah mampu melakukan berbagai kegiatan pengembangan desa wisata. Selain itu, Pokdarwis juga sudah mulai memikirkan langkah selanjutnya untuk pengembangan desa wisata. Secara umum, hal ini tentunya merupakan sinyal positif bagi alternatif pengembangan wisata Kota Batu ke depan.

Tabel 1. Existing Program dan Rencana Pengembangan Desa Wisata

\begin{tabular}{|c|c|}
\hline Existing Program & $\begin{array}{c}\text { Rencana } \\
\text { Pengembangan }\end{array}$ \\
\hline $\begin{array}{l}\text { Coban Talun } \\
\text { a. Air Terjun } \\
\text { b. Pagupon } \\
\text { c. Apache Camp } \\
\text { d. Taman Bunga } \\
\text { e. Alas Pinus } \\
\text { f. Rumah terbalik } \\
\text { g. Gua Jepang } \\
\text { h. Oyot } \\
\text { i. Ayunan } \\
\text { j. Outbond } \\
\text { k. Fasilitas Penunjang } \\
\text { 1) Penginapan } \\
\text { 2) Lahan Parkir }\end{array}$ & $\begin{array}{l}\text { a. Perluasan Toko } \\
\text { Oleh-oleh } \\
\text { b. Inovasi Fasilitas } \\
\text { Pada Camping } \\
\text { c. Wahana Labirin } \\
\text { d. Perluasan Camping } \\
\text { Ground (Paketan) }\end{array}$ \\
\hline
\end{tabular}




\begin{tabular}{|c|c|}
\hline Existing Program & $\begin{array}{c}\text { Rencana } \\
\text { Pengembangan }\end{array}$ \\
\hline $\begin{array}{l}\text { 3) Toilet } \\
\text { 4) Mushola } \\
\text { 5) Ruang Informasi }\end{array}$ & \\
\hline $\begin{array}{l}\text { Coban Puteri } \\
\text { a. Air Terjun } \\
\text { b. Flyaing Fox } \\
\text { c. Spot-spot Foto } \\
\text { d. Off Road } \\
\text { e. Camp Ground } \\
\text { f. Panjat Tebing } \\
\text { g. Outbond } \\
\text { h. Fasilitas Penunjang } \\
\text { 1) Mushola } \\
\text { 2) Kamar Mandi } \\
\text { 3) Warung } \\
\text { 4) Tempat Parkir yang } \\
\text { 5uas } \\
\text { 5) Gazebo }\end{array}$ & $\begin{array}{l}\text { a. Menambah Spot } \\
\text { Foto } \\
\text { b. Kolam Renang } \\
\text { c. Taman Bungga } \\
\text { d. Memperbaiki } \\
\text { Akses Jalan Masuk }\end{array}$ \\
\hline $\begin{array}{l}\text { Coban Rais } \\
\text { a. Spot Foto } 26 \text { buah } \\
\text { b. Outbond } \\
\text { c. Camping } \\
\text { d. Battel ground } \\
\text { e. Air Terjun } \\
\text { f. Fasilitas } \\
\text { Penunjang: } \\
\text { 1) Lokasi Parkir yang } \\
\text { Memadai } \\
\text { 2) Kios } \\
\text { 3) Mushola }\end{array}$ & $\begin{array}{l}\text { a. Pengembangan } \\
\text { Jalan } \\
\text { b. Penambahan Spot } \\
\text { Foto } \\
\text { c. Cottage dari Alam: } \\
\text { Rumah-Rumah } \\
\text { Kayu }\end{array}$ \\
\hline
\end{tabular}

\section{Hasil Analisa}

Hasil analisa data bisa dilihat pada Gambar 2 dan Tabel 2 berikut ini. Berdasar Tabel 2, menunjukkan bahwa: 1) daya tarik desa wisata mempunyai pengaruh positif dan signifikan terhadap citra desa wisata dengan effect size 0,130; 2) Community Based Tourism mempunyai pengaruh positif dan signifikan terhadap citra desa wisata dengan effect size 0,229; 3) Community Based Tourism tidak memperkuat pengaruh daya tarik desa wisata terhadap citra desa wisata

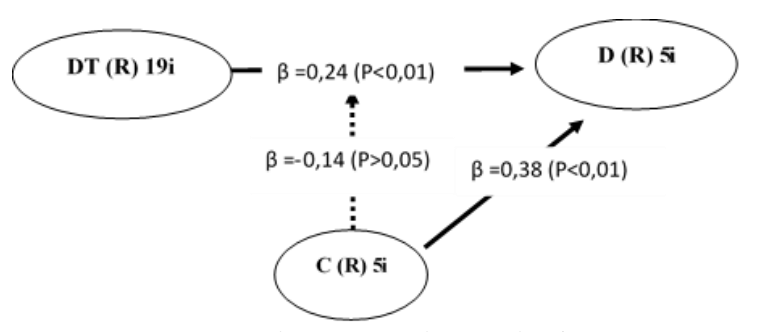

Gambar 2. Path Analysis

Sumber: data diolah

Keterangan: DT : Daya Tarik Desa Wisata

C : Community Based Tourism

D : Citra Desa Wisata

Tabel 2. Hasil Uji Hipotesis

\begin{tabular}{lcccl}
\hline & $\begin{array}{c}\text { Path } \\
\text { Coefficient }\end{array}$ & $\begin{array}{c}P \\
\text { Value }\end{array}$ & $\begin{array}{c}\text { Effect } \\
\text { Size }\end{array}$ & $\begin{array}{l}\text { Hasil Uji } \\
\text { Hipotesis }\end{array}$ \\
\hline $\mathrm{C} \rightarrow \mathrm{D}$ & 0,384 & 0,001 & 0,229 & Diterima \\
$\mathrm{DT} \rightarrow \mathrm{D}$ & 0,245 & 0,003 & 0,130 & Diterima \\
$\mathrm{C} *$ DT $\rightarrow$ D & $-0,144$ & 0,052 & 0,052 & Ditolak \\
\hline
\end{tabular}

Keterangan: DT : Daya Tarik Desa Wisata

C : Community Based Tourism

D : Citra Desa Wisata

\section{Pembahasan}

Dari hasil analisa data terlihat bahwa daya tarik desa wisata dan Community Based Tourism mempunyai pengaruh positif dan signifikan terhadap citra desa wisata. Hal ini berarti semakin menarik atraksi wisata, semakin bagus fasilitas, substruktur dan akses wisata, dan kelayakan tarif desa wisata akan menciptakan citra positif terhadap desa wisata. Begitu juga dengan keberadaan Community Based Tourism yang tercermin dari keramahan masyarakat, pedagang, dan semua sektor jasa wisata, keaktivitas masyarakat dalam pengelolaan wisata, dan profesionalisme masyarakat dalam pengelolaan pariwisata juga membantu menciptakan citra yang baik terhadap desa wisata. Meski Community Based Tourism tidak memperkuat pengaruh daya tarik desa wisata terhadap citra desa wisata tetapi pengaruh langsung Community Based Tourism terhadap citra desa wisata lebih besar daripada pengaruh langsung daya tarik desa wisata terhadap citra desa wisata. Hal ini berarti bahwa Community Based Tourism merupakan faktor penting yang harus diperhatikan untuk membangun citra desa 
wisata. Sangat relevan jika Community Based Tourism harus menjadi peran utama dalam pengembangan desa wisata karena secara umum memang desa wisata menawarkan potensi desanya kepada wisatawan. Sehingga masyarakat desa tersebut harus mampu bekerjasama secara profesional untuk menarik dan melayani wisatawan yang datang ke desanya. Banyak kegiatan yang bisa dilakukan masyarakat desa mulai dari kegiatan kecil menjaga kebersihan, bersikap ramah terhadap wisatawan, memperbaiki jalan sampai dengan kegiatan profesional yang dapat menghasilkan profit untuk desa seperti menyediakan fasilitas umum seperti toilet dan lahan parkir, menambah spot-spot foto yang menarik, dan membuat promo di media sosial. Hal penting yang harus diperhatikan bagi desa wisata untuk bertahan dan berkembang dalam jangka panjang adalah jangan menjadi terlalu "money" oriented, pemberlakuan tarif harus dikelola sedemikian rupa sepadan dengan yang ditawarkan kepada wisatawan dan menjaga "kenyamanan" wisatawan supaya mereka puas dan mau datang kembali atau menceritakan kepuasannya kepada yang lain. Mengingat bahwa industri pariwisata yang diasumsikan harus dimulai dari memahami kebutuhan masyarakat sebagai konsekuensi dari model pengembangan pariwisata berorientasi CBT, maka pengembangan pariwisata haruslah berupaya agar lebih bermanfaat bagi kebutuhan, gagasan dan peluang masyarakat setempat (Pinel DP, 1998). CBT tidak bertujuan untuk memaksimalkan keuntungan bagi investor karena CBT bukan sebuah bisnis wisata melainkan berorientasi pada pemanfaatan sumber daya lingkungan sebagai dampak pariwisata bagi masyarakat. CBT berawal dari strategi pemberdayaan masyarakat, menggunakan pariwisata sebagai alat untuk memperkuat kapasitas masyarakat pedesaan/lokal untuk berorganisasi.

Oleh karena itu, untuk meningkatkan peran CBT dalam hal ini dilakukan oleh Pokdarwis disarankan agar pemerintah memberikan perhatian pada kegiatan pemberdayakan Pokdarwis melalui beberapa hal: 1) Sosialisasi dan pelatihan untuk membuka pikiran masyarakat tentang pentingnya dan manfaat dari pengembangan kegiatan pariwisata di daerahnya yang dekat dengan destinasi wisata; 2) Memfasilitasi pemilihan pemimpin yang dapat diandalkan; dan 3) Melakukan koordinasi dan memberikan bantuan pendampingan secara intensif. Secara umum dapat disimpulkan bahwa perlu didukung dan dipupuk terus menerus keberadaan Pokdarwis dengan tujuan dapat memainkan peran yang lebih optimal dalam memobilisasi keterlibatan masyarakat untuk menciptakan lingkungan dan atmosfer yang kondusif bagi pertumbuhan dan pengembangan aktivitas pariwisata di sekitar destinasi wisata (Hidayatullah, Rachmawati, Khouroh, \& Windhyastiti, 2018).

\section{Kesimpulan}

Hasil penelitian menunjukkan: 1) daya tarik desa wisata mempunyai pengaruh yang positif dan signifikan terhadap citra desa wisata; 2) Community Based Tourism mempunyai pengaruh positif dan signifikan terhadap citra desa wisata; 3) Community Based Tourism tidak memperkuat pengaruh daya tarik desa wisata terhadap citra desa wisata, tetapi pengaruh langsung Community Based Tourism terhadap citra desa wisata lebih besar daripada pengaruh langsung daya tarik desa wisata terhadap citra desa wisata.

Berdasarkan hal penelitian tersebut maka perlu didukung dan dipupuk terus menerus keberadaan Pokdarwis dengan tujuan Pokdarwis dapat memainkan peran yang lebih optimal dalam memobilisasi keterlibatan masyarakat untuk menciptakan lingkungan dan atmosfer yang kondusif bagi pertumbuhan dan pengembangan aktivitas pariwisata di sekitar destinasi wisata.

\section{DAFTAR PUSTAKA}

Bahaire, T., \& Elliott-White, M. 1999. Community Participation in Tourism Planning and Development in the Historic City of York, England. Current Issues in Tourism, 2(2-3), 243-276. https://doi.org/10.1080/1368350990866 7854 
Chi Gengqing. 2005. A Study of Developing Destination Loyalty Model. (July). Retrieved from http://digital.library.okstate.edu/etd/umi -okstate-1513.pdf

Coban S. 2012. The effects of the image of destination on tourist satisfaction and loyalty: The case of Cappadocia. European Journal of Social Sciences, 29(2), 222-232.

Getz, D., \& Jamal, T. B. 1994. The Environment-Community Symbiosis: A case for Collaborative Tourism Planning. Journal of Sustainable Tourism, 2(3), 152-173. https://doi.org/10.1080/0966958940951 0692

Gunn, C. A. 1988. Vacationscape Designing Tourist Regions (2nd ed). Retrieved from

http://openlibrary.org/books/OL240401 $2 \mathrm{M}$

Hidayatullah, S., Rachmawati, I. K., Khouroh, U., \& Windhyastiti, I. 2018. Development of Tourist Village Model Through "Pokdarwis" Empowerment and Information Technology Utilization. European Journal of Business and Management, 10(23), 22-28. https://doi.org/10.7176/ejbm-10-23-12

Milman A, \& Pizam A. 1995. The Role of Awareness and Familiarity with a Destination: The Central Florida Case. Journal of Travel Research, 33(3), 2127.

https://doi.org/10.1177/0047287595033 00304

Murphy, P. E. 1985. Tourism : A Community Approach. Retrieved from https://baclac.on.worldcat.org/oclc/715745106

Permen Kebudayaan dan Pariwisata. 2010. Peraturan Menteri Kebudayaan dan Pariwisata tentang Pedoman Umun Program Nasional Pemberdayaan Masyarakat (PNPM) Mandiri Pariwisata Melalui Desa Wisata. 1-21. Retrieved from http://www.kemenpar.go.id/userfiles/fil e/1_ Permen PNPM Mandiri Pariwsata Desa Wisata dan lampiran.pdf
Pinel DP. 1998. Community-based Tourism Planning Process Model.

Pitana IG, \& Diarta I K. S. 2009. Pengantar Ilmu Pariwisata. Retrieved from https://www.academia.edu/35969060/P engantar_Ilmu_Pariwisata

Statistik, B. P. 2020. Kota Batu Dalam Angka 2020. Batu.

Surachman, S. 2008. Dasar-Dasar Manajemen Merek: Alat Pemasaran Untuk Memenangkan Persaingan. Retrieved from http://elib.ibs.ac.id/index.php?p=show detail\&id $=2577 \&$ keywords $=$

Utama, I. R. 2017. Hubungan faktor motivasi wisatawan dan citra destinasi pariwisata. (July), 1-45. Retrieved from https://www.researchgate.net/publicatio n/318402151_Hubungan_Faktor_Motiv asi_Wisatawan_dan_Citra_Destinasi_P ariwisata

Vollero, A., Conte, F., Bottoni, G., \& Siano, A. 2018. The influence of community factors on the engagement of residents in place promotion: Empirical evidence from an Italian heritage site. International Journal of Tourism Research, 20(1), 88-99. https://doi.org/10.1002/jtr.2164

Widya Amelia. 2016. Peran Community Development Dalam Mendukung Pembentukan Citra Pariwisata Daerah. Retrieved from http://digilib.uinsuka.ac.id/21280/2/12730087_BabI_IV-atau-V_Daftar-Pustaka.pdf 